\section{Carbon-based Nanoelectromechanics}

Sang Wook LEE

Thanks to the rapid development of nano-lithography techniques, the carbon-based nanoelectromechanical system (NEMS) has been widely studied during the last several years. In this article, the carbon-based NEMS will be introduced. First, the concept and the physical importance of an electromechanical system are described. Then, several interesting carbon-nanotube- and graphenebased nanoelectromechanical devices are introduced, and their fundamental mechanical and electromechanical properties are discussed. Finally, possible applications of the carbon-based NEMS for future electronic systems will be suggested.

리소그래피 기술이 발전하게 되면서 나노미터 스케일 전극 구조 제작이 연구실 수준에서 가능하게 되었다. 이에 따라 여 러 가지 나노 소재를 이용하여 다양한 형태의 나노 소자가 제작되고 이들 소자의 전기적, 역학적 특성에 대한 연구들이 지난 10 여 년 동안 빠른 속도로 이루어져 왔다. 이러한 소자 연구가 발전할 수 있게 된 큰 계기 중 하나로 탄소나노튜브, 반도체 나노선과 같은 일차원 나노구조가 합성되어 저차원 물질의 물리적 특성에 대한 관심이 커지게 된 점을 들 수 있 다. 저차원 나노 소재의 단일 나노 구조에 나노 리소그래피를 이용하여 소자를 제작하고 이를 통해 중시계에서의 다양한 물리적 특성을 실험적으로 연구할 수 있게 되었다. 지난 몇 년간 그래핀에 대한 연구가 활발하게 이루어지고 특히 그래 핀 소자의 물리적 특성에 대한 많은 연구 보고가 빠른 시간 에 이루어질 수 있게 된 것도 그동안 저차원 나노구조를 이

\section{저자약력}

이상욱 교수는 서울대학교 물리학부에서 고체물리실험으로 이학박사 학위 (2005)를 취득한 후 2007년까지 스웨덴 예테보리 대학 물리학부에서 박사 후 연구원을 거친 후 2008년부터 현재까지 건국대학교 물리학부 조교수를 거쳐 부교수로 재작하고 있다. 저차원 나노구조를 이용한 나노 전자 소자 및 나노 역학 소자의 제작과 특성 분석에 관심을 갖고 연구를 진행하고 있 다. (leesw@konkuk.ac.kr)
용한 소자 연구를 통해 쌓아온 소자 제작에 대한 경험이 있 었기 때문에 가능하였다.

지난 몇 년간 탄소 기반 단일 나노 구조물에 대한 물성 연 구 활동 중 특히 나노 전자소자에 대한 연구가 활발히 연구 되어왔고 특히 탄소나노튜브 및 그래핀에 대한 다양한 연구 활동들이 물리학과 첨단기술에도 여러 차례 소개된 바 있다. 이 글에서는 최근 활발하게 연구되고 있는 나노 전기역학 시 스템에 대해 소개하고 탄소 나노튜브, 그래핀 기반 나노 구조 물을 이용한 나노 전기역학 소자의 물리적 특성과 응용 가능 성에 대해 논의하고자 한다.

\section{나노 전기역학 시스템}

전기역학 시스템은 전기적 자유도(electrical degree of free$\mathrm{dom}$ )와 역학적 자유도(mechanical degree of freedom)가 결 합된 시스템을 말한다. 18세기 후반 쿨롱이 고안한 대전된 두 물체 사이에 작용하는 전기력을 측정하는 장치는 전기 역학 시 스템의 좋은 예이다. 쿨롱은 비틀림 저울을 이용하여 비틀림 저 울 끝에 대전된 공을 매달고 또 다른 공을 대전시켜서 이 둘 사 이의 정전기력에 의해 비틀림 저울에 매달린 공이 회전할 수 있도록 하였다. 여기서 비틀림 저울이 정전기력을 역학적인 힘 으로 변환시키는 역할을 하는 전기역학 시스템으로 작용한다. (그림 1(a)) 즉 전하를 가진 비틀림 저울이 전기적 자유도와 역 학적 자유도를 커플링(coupling)시킴으로써 매우 정밀하게 정 전기력을 구해내고 이를 통해 쿨롱의 법칙을 유도할 수 있었다. 두 개의 자유도가 커플링된 전기역학 시스템을 통해 매우 작은 힘의 변화를 측정할 수 있다는 교훈을 18 세기 말 쿨롱의 실험 을 통해 배우게 되었다. 나노 전기역학 시스템은 이러한 전기역 학 시스템의 크기를 나노미터 스케일로 줄인 것이다.(그림 $1(\mathrm{~b}))^{[1]}$ 마이크로 스케일 전기역학 시스템에 비해 나노 전기역학 시스 템이 가진 흥미로운 차이점은 나노 스케일로 소자의 크기가 줄 어들게 되면서 양자역학적인 전기역학 현상을 실험적으로 연구 할 수 있게 된 점이다. 1990년대 중반 캘리포니아 공과대학의 Roukes 그룹에서 공중에 매달린 나노 스케일 실리콘 빔에 자 기장을 걸고 $\mathrm{ac}$ 전류를 가했을 때 역학적으로 공명하는 현상을 관찰한 보고가 나노 전기역학 시스템 연구의 단초가 되었다. ${ }^{[2]}$ 이후 지난 수년간 나노 전기역학 시스템 연구가 활발히 진행되 


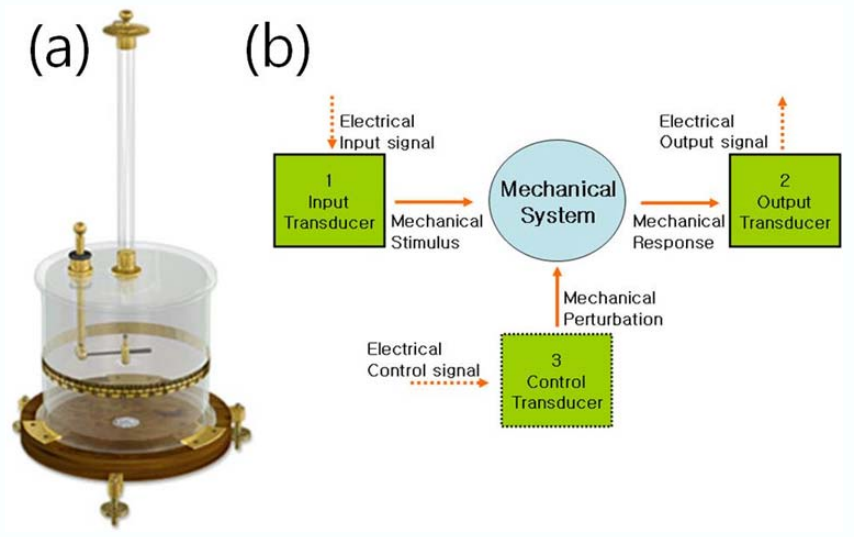

Fig. 1. (a) Torsional balance for Coulomb's experiment. (b) Concept of nanoelectromechanical system. ${ }^{[1]}$

어 높은 Q값(quality factor)을 가지고 높은 주파수에서 전기역 학 시스템의 공명이 일어날 수 있는 소자를 개발하고 공명주파 수를 감지할 수 있는 측정 시스템을 개발해왔다. 이러한 연구 개발을 통해 현재는 $10^{-21}$ (zepto) 그램, 심지어 $20^{-24}$ (yocto) 그 램 수준의 작은 질량 변화를 전기역학 시스템의 공명 주파수 변화를 통해 측정할 수 있게 되었고 이를 응용하여 원자의 개 수를 구별할 수 있는 수준의 질량 센서, 또는 소자 표면에서 화 학적 반응에 의한 민감한 질량 변화를 감지하는 나노 바이오센 서 등과 같은 응용 소자 연구도 활발히 진행되고 있다. ${ }^{[1,3]}$ 이와 더불어 나노 전기역학 소자를 이용한 기초 물리 연구들 또한 활발히 진행되고 있는데, 예를 들어 미세 질량 측정과 더불어 나노 전기역학 시스템의 미세 변위를 측정함으로써 변위의 양 자역학적 불확정성 측정의 한계를 탐구하기 위한 소자 제작 및 측정 방법이 개발되고 있고 카시미어 효과(Casimir effect)와 같은 양자 전기역학 현상을 나노 전기역학 시스템을 통해 알아 보려는 노력들이 이러한 연구들의 예가 될 수 있겠다. ${ }^{[4,5]}$

이와 같이 나노 전기역학 시스템을 통해 작은 세계에서의 힘의 관계 또는 미세한 질량 변화 등을 정밀하게 연구함으로 써 다양한 역학적 현상을 탐구할 수 있게 되었다.

\section{탄소 나노튜브를 이용한 나노 전기역학 소자}

탄소나노튜브는 1991년 세상에 알려진 이후로 지금까지 그 물성 및 응용가능성에 대해 폭발적으로 연구가 진행되고 있는 물질이다. 탄소나노튜브는 탄소 육각 구조가 대롱형태로 말리 는 형태(손지기(chirality))에 따라 금속성이 되거나 갭을 가진 반도체성이 될 수 있어서 탄소나노튜브의 전기적 특성을 연구 하기 위한 전자소자 연구가 많이 이루어졌다. 흥미로운 전기적 특성 이외에 탄소나노튜브는 역학적으로도 매우 강한 특성을 가지고 있어서 결함이 없는 단겹 탄소나노튜브의 경우 $1 \mathrm{TPa}$
이상의 영률을 가지고 있는 것으로 알려져 있다. 흥미로운 전기 전도도와 높은 영률을 동시에 가지고 있는 탄소나노튜브는 나 노 전기역학 시스템의 소재로 매우 적합한 물질이다. 탄소나노 튜브를 이용하여 전기역학 소자를 제작하기 위해서는 나노튜브 가 움직일 수 있도록 나노튜브를 공중에 매다는 공정이 필요하 다. 초기의 소자는 탄소나노튜브가 기판에 놓여있으면 그 위에 리소그래피를 통해 전극을 제작하여 나노튜브의 양단을 지지하 고 나노튜브 주변의 기판을 선택적으로 파내는 식각작업을 통 해 공중에 매달린 구조를 제작하였다.[6] 이후 리소그래피 공정 을 개발하여 식각작업 없이 간단히 탄소나노튜브를 공중에 띄 울 수 있게 되고 ${ }^{[7]}$ 나아가 탄소나노튜브를 우리가 원하는 위치 에 매달 수 있는 위치제어 기술이 개발되어서 공중에 매달린 탄소나노튜브 아래에 여러 가지 나노 구조를 패턴할 수 있는 방법이 개발되었다. ${ }^{[8,9]}$ 이러한 나노 공정의 개발로 인해 탄소나 노튜브를 이용한 다양한 전기역학 소자들이 만들어질 수 있게 되었다.

초기의 탄소나노튜브 기반 나노전기역학 시스템 연구는 탄소 나노튜브의 기본 역학특성, 전기역학 특성을 공부하는 분야와 흥미로운 전기역학 소자 구조를 제작하고 이들의 물리적 현상 을 관찰하는 분야에서 두각을 보이기 시작하였다. 탄소나노튜 브의 역학적 특성은 나노튜브의 양단을 고정시켜서 빨래줄처럼 매달아 놓은 후 원자 힘 현미경의 팁을 이용하여 공중에 매달린 튜브를 눌러서 힘-거리 측정을 하거나 공중에 매달린 튜브에 교 류신호를 가하여 튜브가 역학적으로 흔들릴 때 나타나는 공명 주파수를 측정한 연구들을 통해 보고되었다. ${ }^{[7,10-12]}$ 초기의 선도 적인 전기역학적 특성 연구에는 미국 스탠포드 대학 Dai 그룹 과 코넬 대학 McEuen 그룹에서 동시에 발표한 $\mathrm{AFM}$ 을 통해 공중에 매달린 탄소나노튜브에 strain을 가하면서 전기전도 특 성이 변화하는 것을 관찰한 보고가 있다. ${ }^{[13,14]}$ 리소그래피 기술

\section{REFERENCES}

[1] K. L. Ekinci and M. L. Roukes, Rev. Sci. Inst. 76, 061101 (2005).

[2] A. N. Cleland and M. L. Roukes, Appl. Phys. Lett. 69, 2653 (1996).

[3] Akram S. Sadek, Rassul B. Karabalin, Jiangang Du, Michael L. Roukes, Christof Koch and Sotiris C. Masmanidis, Nano Lett. 10, 1769 (2010)

[4] M. Blencowe, Phys. Rep. 395, 159 (2004).

[5] E. Buks and M. L. Roukes, Nature 419, 119 (2002).

[6] J. Nygård and D. H. Cobden, Appl. Phys. Lett. 79, 4216 (2001).

[7] G. T. Kim, G. Gu, U. Waizmann and S. Roth, Appl. Phys. Lett. 80, 1815 (2002).

[8] S. W. Lee, D. S. Lee, H. Y. Yu, E. E. B. Campbell and Y. W. Park, Appl. Phys. A 78, 283 (2004).

[9] S. W. Lee, A. Eriksson, A. A. Sourab and E. E. B. Campbell, J. Korean Phys. Soc. 55, 957 (2009). 


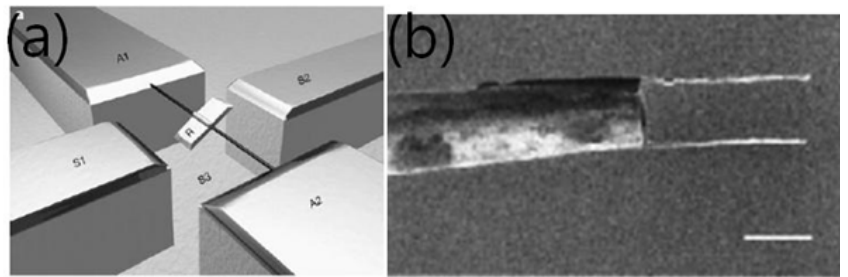

Fig. 2. (a) Carbon nanotube based rotational actuator. ${ }^{[15]}$ (b) Carbon nanotube tweezers. ${ }^{[16]}$

이 개발되어 전극 패턴 또는 3차원 구조를 만드는 탑다운 (top-down) 방식과 이러한 구조에 탄소나노튜브를 연결하기 위 한 바텀업(bottom-up) 방식을 결합할 수 있게 되면서 여러 가 지 아이디어를 통해 다양한 형태의 새로운 나노 전기역학 소자 가 제작되었는데 그림 2에서 보여주는 것과 같이 공중에 매달 린 탄소나노튜브를 이용한 회전하는 나노 구조 또는 탄소나노 튜브 핀셋과 같은 재미있는 전기역학 소자들이 1990년대 말부 터 2000년대 초에 개발되었다. ${ }^{[15,16]}$

최근의 탄소나노튜브 기반 나노전기역학 소자의 연구는 탄소 나노튜브의 뛰어난 역학적 특성과 전기전도성을 최대한 활용하 여 양자 전기역학 특성을 연구하는 분야와 새로운 개념의 미래 소자로서 가능성을 찾는 분야로 연구의 관심이 옮겨가고 있다.

미국 버클리 대학 Zettl 그룹과 네덜란드 델프트공대 van der Zant 그룹에서 탄소나노튜브 공진기의 공진주파수와 Q값을 높 여서 나노튜브 공진기의 전기역학적 자극에 대한 반응 감도를 높이는 연구를 진행하여 나노튜브의 역학적 공진주파수가 1.3 $\mathrm{GHz}$ 이상이 되고 $\mathrm{Q}$ 값이 10 만 이상이 되는 탄소나노튜브 공진 기를 제작할 수 있게 되었다. ${ }^{[17,18]}$ 고주파에서 작동하는 탄소나 노튜브 전기역학 소자가 개발되고 미세한 역학적 거동 변화의 신호를 측정할 수 있게 되면서 그림 3에서 보여주는 바와 같이 탄소나노튜브를 지나가는 전자의 터널링 현상과 탄소나노튜브 의 역학적 공진에 의한 전자의 역학적인 움직임이 강하게 커플 링되는 현상을 측정할 수 있게 되었다. ${ }^{[19]}$ 저온에서 공중에 매 달린 탄소나노튜브는 양자점과 같이 행동을 하게 되어 게이트 전압을 증가시키면서 양단의 전극에 전류를 측정하면 쿨롱 장 벽(Coulomb blockade)에 의해 게이트 전압 변화에 주기적으 로 전자가 탄소나노튜브로 터널링을 통해 이동하게 된다. 이와 동시에 탄소나노튜브가 역학적 공명을 일으키도록 외부 신호를 주고 공명주파수를 읽어내면 탄소나노튜브에 전자가 하나씩 터 널링됨에 따라 나노튜브의 공진주파수가 일정하게 증가하는 것 을 확인할 수 있었다. 이는 탄소나노튜브에 전자가 하나 더해짐 에 따라 공중에 매달린 나노튜브의 장력이 증가하고 이 때문에 나노튜브의 스프링 상수가 커지게 되는 원인으로 분석되었다. 고주파에서 공명하는 탄소나노튜브 기반 전기역학 시스템을 통해 RF 소자로서 응용 가능성을 탐구하는 연구도 진행되었다.

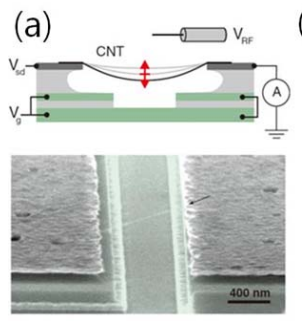

(b)

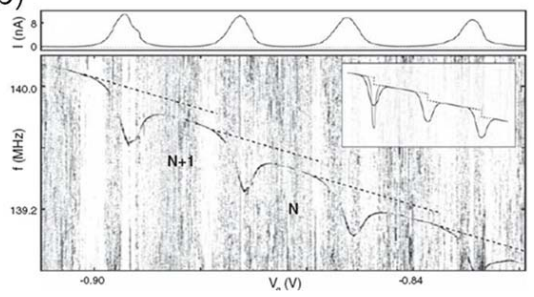

Fig. 3. (a) Schematics and electron microscope image of carbon nanotube based electromechanical resonator with high resonance frequency and high quality factor. (b) Resonance signal versus frequency and gate bias measured of the CNT resonator. ${ }^{[19]}$

이중 미국 버클리 대학 Zettl 그룹에서 발표한 탄소나노튜브 라 디오 연구는 탄소나노튜브 기반 나노 전기역학 시스템의 RF 응 용가능성을 보여준 가장 흥미로운 예들 가운데 하나이다. ${ }^{[20]}$ 외 팔보 형태의 탄소나노튜브 나노 전기역학 공진기를 전계 방출 (field emission) 팁으로 동시에 사용하여 탄소나노튜브 공진기 하나가 안테나, 튜너 및 복조기(demodulator)로 모두 사용될 수 있는 라디오를 구현하였다. 음악 신호가 동조(modulation)된 특정 라디오 주파수가 탄소나노튜브에 들어오면 역학적 공명을 일으키면서 전자를 양극에 방출하고 방출된 전자에 의한 전류신 호를 증폭하여 스피커에 전달함으로써 음악신호가 출력되는 소 자를 구현하는 원리이다. 이와 같이 전기역학 시스템을 이용하 면 이전의 전자소자 기반 시스템과는 전혀 다른 형태를 가지면 서도 현재의 전자소자들보다 효율적인 시스템을 만들 수 있는

\section{REFERENCES}

[10] P. Poncharal, Z. L. Wang, D. Ugarte and W. A. de Heer, Science 283, 1513 (1999).

[11] S. T. Purcell, P. Vincent, C. Journet and V. T. Binh, Phys. Rev. Lett. 89, 276103 (2002)

[12] V. Sazonova, Y. Yaish, H. Üstünel, D. Roundy, T. A. Arias and P. L. McEuen, Nature 431, 284 (2004).

[13] Jien Cao, Qian Wang and Hongjie Dai, Phys. Rev. Lett, 90, 157601 (2003).

[14] E. D. Minot, Yuval Yaish, Vera Sazonova, Ji-Yong Park, Markus Brink and Paul L. McEuen, Phys. Rev. Lett. 90, 156401 (2003).

[15] A. M. Fennimore, T. D. Yuzvinsky, W. Han, M. S. Fuhrer, J. Cumings and A. Zettl, Nature 424, 408 (2003).

[16] P. Kim and C. M. Lieber, Science 286, 2148 (1999).

[17] H. B. Peng, C. W. Chang, S. Aloni, T. D. Yuzvinsky and A. Zettl. Phys. Rev. Lett. 97, 087203 (2006).

[18] A. K. Huttel, G. A. Steele, B. Witkamp, M. Poot, L. P. Kouwenhoven and H. S. J. van der Zant, Nano Lett. 9, 2547 (2009).

[19] G. A. Steele, A. K. Hüttel, B. Witkamp, M. Poot, H. B. Meerwaldt, L. P. Kouwenhoven and H. S. J. van der Zant, Science 325, 1103 (2009).

[20] K. Jensen, J. Weldon, H. Garcia and A. Zettl, Nano Lett. 7, 3508 (2007). 


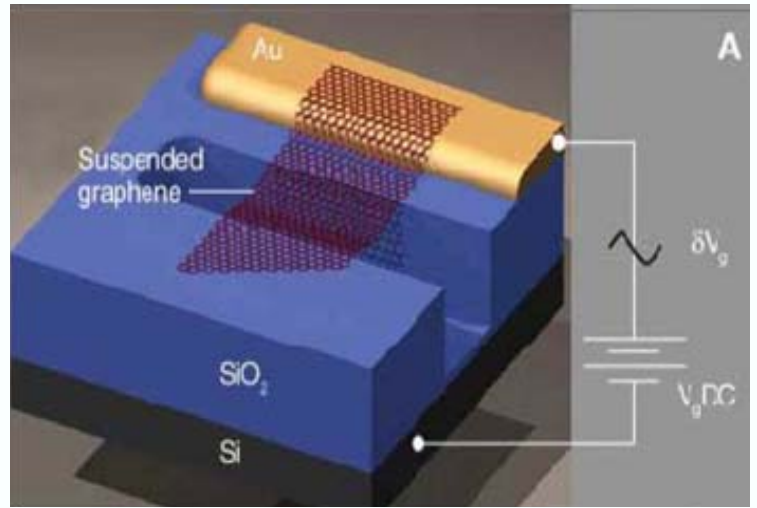

Fig. 4. Graphene resonator. ${ }^{[23]}$

가능성을 보여주었다. 탄소나노튜브 공진기의 공명주파수가 $\mathrm{GHz}$ 이상의 고주파에서도 매우 넓은 튜닝 가능성(tunability)을 가짐을 이론적으로 예측하였고 ${ }^{[1]}$ 이를 바탕으로 현재 사용하고 있는 핸드폰과 같은 무선통신 장치의 송수신기(transceiver)의 구성요소로 결합하려는 시도도 있었다. 이러한 시도는 현재 모 바일 통신에서 통화에 적용되고 있는 주파수 범위뿐 아니라 블 루투스, 무선랜 등과 같은 여러 주파수 영역에 대한 송수신을 하 나의 소자로 가능하게 할 수 있다는 점에서 무선통신 연구 분야 에서 중요하게 여겨졌었다. 실제 실험을 통해 탄소나노튜브의 공명을 전기적 측정으로 직접 검출해내고 주파수 튜닝이 이론적 인 예측과 정성적으로 일치함을 보여주는 연구보고가 있었지만 ${ }^{[2]}$ 입력신호 대비 출력 신호 값이 너무나 적게 얻어지는 문제점 때 문에 더 이상의 혁신적인 개발은 이루어지지 않고 있는 것으로 파악된다. 탄소나노튜브와 전극간의 접촉저항이 수 $\mathrm{k} \Omega$ 이하로 줄이는 것이 어려워서 전파공학에서 신호 전달을 위해 중요하게 여겨지는 50옴 임피던스 매칭(impedance matching)이 가능하 지 않은 것이 이러한 문제점의 가장 큰 원인으로 분석된다.

\section{그래핀을 이용한 나노 전기역학 소자}

그래핀도 $1 \mathrm{TPa}$ 이상의 영률을 가지고 있으면서 전기전도 도가 금속만큼 우수하여 탄소나노튜브와 마찬가지로 나노전기 역학 시스템에 사용될 수 있는 가장 좋은 소재로 평가된다. 탄 소나노튜브가 기타 줄이 진동하는 것과 같은 1 차원 나노구조 의 역학적 거동을 연구하는데 유용한 소재였다면 그래핀은 드 럼을 연주할 때 드럼에서 나타날 수 있는 2 차원 거동을 나노 스케일에서 연구할 수 있다는 것은 탄소나노튜브를 이용한 나 노 전기역학 시스템과는 또 다른 흥미로운 점이라 할 수 있다. 2004년 스카치테이프를 이용하여 단겹 그래핀을 얻어낼 수 있게 되면서 그래핀 기반 소자들이 폭발적으로 연구되었다. 단 겹 그래핀을 이용한 전기역학 소자의 연구도 탄소나노튜브 연 구의 경험이 바탕이 되어 비교적 빠른 속도로 이루어졌다. 전
기역학 소자를 제작하기 위해 그림 4와 같이 기판을 먼저 식 각하여 도랑(trench) 구조를 만들어 놓은 다음 그 위에 역학적 박리법으로 분리한 그래핀을 붙여서 공중에 매달린 그래핀 구 조를 만들고 이로부터 그래핀의 역학적 공명 현상을 관찰한 그래핀 기반 공진기 연구가 먼저 보고되었다. ${ }^{[23]}$ 이후 그래핀 을 원하는 위치에 놓을 수 있는 마이크로 전사(transfer) 방법 을 통해 ${ }^{[24]}$ 소자 제작의 수율을 높일 수 있었고 대면적 그래핀 을 CVD 방법으로 합성하면서 어레이(array) 형태의 그래핀 전기역학 소자에 대한 연구가 진행되었다. ${ }^{[25]}$ 이렇게 제작된 공중에 매달린 그래핀 구조의 기본 역학적 공명 특성과 더불 어 주파수 튜닝 가능성에 대한 연구가 진행되었다.

탄소나노튜브를 이용한 전기역학 소자에 대한 소개 마지막 부분에서 언급한 것과 같이 나노튜브-전극간 높은 접촉저항에 의한 임피던스 매칭의 어려움이 RF 소자로서 탄소나노튜브를 응용할 때 문제가 될 수 있다. 만약 그래핀을 공진기로 사용 한다면 2차원 구조의 특성상 전극과 그래핀간의 접촉 면적이 넓기 때문에 접촉저항에 의한 임피던스 매칭 문제는 해결할 수 있을 것으로 기대된다. 이러한 2차원 구조특성 때문에 전 기역학 시스템 연구 분야에서도 그래핀이 탄소나노튜브보다 많은 연구진에 의해 연구가 수행되고 있는 것으로 보인다.

또한 2 차원 구조를 가진 그래핀은 실리콘 반도체 공정을 많이 변화시키지 않고 소자를 제작할 수 있는 이점이 있어서 탄소나노튜브 기반 전기역학 소자에서 연구되었던 선행경험 을 그래핀에 쉽게 적용시킬 수 있었다. 이 때문에 단겹 그래 핀을 분리하게 된 이래로 기반 전자소자의 연구가 폭발적으 로 수행된 것과 맞물려 전기역학 소자 연구도 활발하게 연구 될 수 있었다. 최근 그래핀을 이용한 전기역학 소자 연구에서 의 이슈는 웨이퍼 스케일에서 항상성 있는 소자를 제작하고 그 특성을 연구하려는 노력과 더불어, ${ }^{[26]}$ 탄소나노튜브 연구

\section{REFERENCES}

[21] L. M Jonsson, S. Axelsson, T. Nord, S. Viefers and J. M. Kinaret, Nanotechnology 15, 1497 (2004).

[22] A. Eriksson, S. W. Lee, A. A. Sourab, A. Isacsson, R. Kaunisto, J. M. Kinaret and E. E. B. Campbell, Nano Lett. 8, 1224 (2008).

[23] J. S. Bunch1, A. M. van der Zande, S. S. Verbridge, I. W. Frank, D. M. Tanenbaum, J. M. Parpia, H. G. Craighead and P. L. McEuen, Science 315, 490 (2007).

[24] L. Jiao, B. Fan, X. Xian, Z. Wu, J. Zhang and Z. Liu, J. Am. Chem. Soc. 130, 12612 (2008).

[25] A. M. van der Zande, R. A. Barton, J. S. Alden, C. S. Ruiz-Vargas, W. S. Whitney, P. H. Q. Pham, J. Park, J. M. Parpia, H. G. Craighead and P. L. McEuen, Nano Lett. 10, 4869 (2011).

[26] K. M. Milaninia, M. A. Baldo, A. Reina and J. Kong, Appl. Phys. Lett. 95, 183105 (2009). 
와 같은 양상으로 그래핀 나노 공진기의 역학적 공명주파수 및 Q값을 높여서 2차원 양자 전기역학 특성을 연구하려는 노 력이 함께 진행되고 있다. ${ }^{[27]}$ 이뿐 아니라 탄소나노튜브 연구 와 마찬가지로 그래핀에 역학적인 당김힘을 가하면서 동시에 전기적 특성을 탐구하는 인시츄 전기역학 특성 연구, 그래핀 에 역학적인 자극을 통해 그래핀의 전자구조 대칭성을 변화 시켜 그래핀에 갭을 만들고자 하는 시도도 이루어지고 있다.

\section{탄소기반 나노 전기역학 시스템의 미래소자로서의 가능성}

포스트 실리콘 시대에 실리콘을 대체할 수 있는 나노 소재 기반 전자 시스템에 대한 연구가 물리학자들을 중심으로 논 의되고 있다. 이중 탄소나노튜브, 그래핀이 기반이 된 소위 “탄소만으로 이루어진 전자 시스템"(all carbon electronics) 에 대한 연구도 최근 시작되어 국내외 연구자들이 탄소 기반 나노소재의 미래 전자 시스템으로의 가능성 연구를 수행하고 있다. 현재의 실리콘 기반 산업과 비교했을 때 탄소만으로 이 루어진 전자 시스템은 아직 경쟁자체가 불가능하지만 탄소 기반 나노구조물이 포스트 실리콘 시대 전자 시스템 소재로 가장 강력하게 대두되고 있는 후보 중 하나임은 분명하다. 트 랜지스터가 처음 발명되고 상품으로 나오게 된 1950년대 당 시 미국의 신문에서 “생긴 것도 이상하고 값도 비싼 트랜지스 터가 어떻게 진공관을 대체할 수 있겠습니까?” 하며 진공관 광고를 했다는 것을 생각해 보면 all carbon electronics의 가능성이 아주 터무니없는 상상만은 아닐 것으로 생각된다.

탄소 기반 나노 전기역학 시스템 연구 영역에서도 소자들의 포스트 실리콘 시대를 대비한 응용 가능성을 탄소기반 나노 전 자 소자 연구와는 조금 다르지만 재미있는 방향으로 새로운 개 념의 응용 소자를 제시하는 연구 결과들이 최근 보고되고 있다. 공중에 매달린 탄소나노튜브에 바닥 전극으로부터 전압을 가하 였을 때 정전기력에 의해 바닥에 닿는 순간과 떨어지는 순간의 전압값의 이력현상이 나타나는 것을 이용하여 전기역학적 메모 리가 가능함을 보여준 이론, 실험연구가 10여 년 전부터 수행되 고 있다. ${ }^{[28,29]}$ (그림 5(a)) 마이크로 전기역학 시스템과 탄소나노 튜브를 플로팅 게이트를 매개로 결합하여 플래시메모리보다 속 도, 전력소모 면에서 뛰어난 메모리 소자를 개발한 연구가 최근 보고되었고 ${ }^{[0]}$ 이후 이 소자의 개념을 그대로 가지면서 마이크로 전기역학 시스템을 그래핀 기반 전기역학 소자로 바꾸어 소형화, 집적화하려는 연구가 현재 진행 중이다. 탄소나노튜브 트랜지스 터 위에 공중에 매달린 그래핀을 게이트로 사용하여 게이팅을 하면서 그래핀이 탄소나노튜브에 가깝게 움직이게 함으로써 트 랜지스터의 효율을 현재 실리콘 기반 $\mathrm{CMOS}$ 트랜지스터가 가진 효율보다 높일 수 있는 가능성을 보인 연구도 최근 보고되었다.
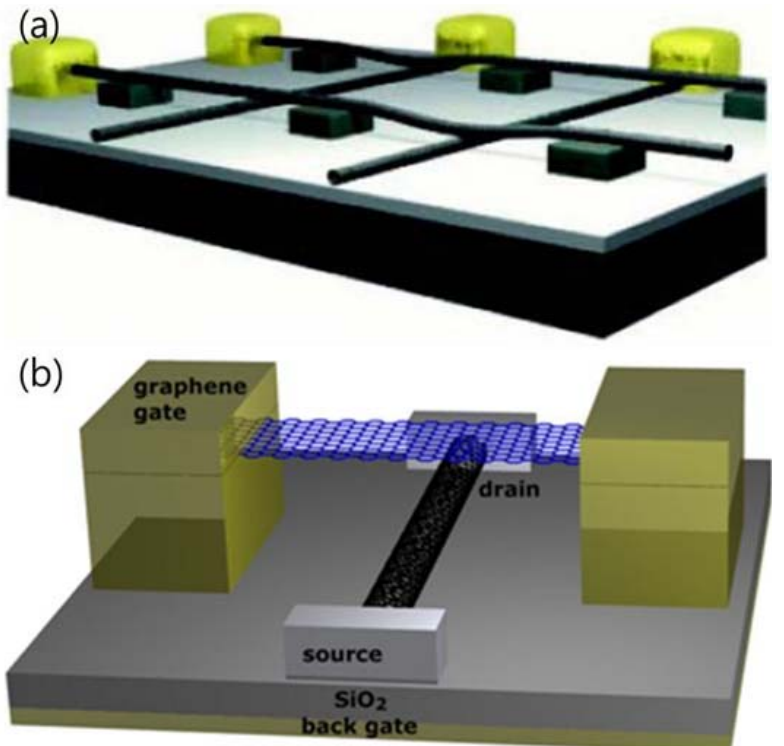

Fig. 5. (a) Carbon nanotube based nanoelectromechanical memory. ${ }^{\text {[29] }}$ (b) Carbon nanotube field effect transistor with suspended graphene moving gate. ${ }^{[31]}$

(그림 $5(\mathrm{~b}))^{[31]}$ 이처럼 전기역학 시스템을 이용하여 이 글의 시작 부분에 언급한 바와 같이 전기적 자유도와 역학적 자유도를 결 합함으로써 지금까지와는 다른 개념의 다양한 소자들이 많은 아 이디어를 통해 계속해서 개발될 수 있다. 현 시점에서는 나노 전 기역학 소자들의 움직임을 자유롭게 제어하기가 쉽지 않고 나노 소자들의 재연성이나 항상성이 낮기 때문에 가까운 미래에 탄소 기반 전기역학 소자가 우리 생활을 바꾸기는 어려울 것이다. 하 지만 지금까지 탄소 기반 나노 전기역학 시스템 연구 보고들을 보면 분명 전기역학 시스템 연구는 미래소자에 대한 우리의 생 각의 범위를 넓혀주고 있는 것은 분명하다. 앞으로도 탄소기반 나노소재를 이용한 전기역학 시스템을 통해 매우 미세한 역학적 반응을 정밀하게 관찰하여 여러 가지 양자 전기역학적 특성을 밝히는 연구와 더불어 실질적인 미래소자 응용 가능성에 대한 연구가 계속해서 활발하게 진행될 것으로 예측된다.

\section{REFERENCES}

[27] For the further reference of recent progress on the graphene mechanics, find the abstracts of Session W7: Focus Session: Graphene Devices - Mechanical Effects in APS 2012 march meeting.(http://meetings.aps.org/Meeting/MAR12/Sessionl ndex2/?SessionEventID=169142).

[28] J. M. Kinaret, T. Nord and S. Viefers, Appl. Phys. Lett. 80, 1287 (2003).

[29] T. Rueckes, K. Kim, E. Joselevich, G. Y. Tseng, C. L. Cheung and C. M. Lieber, Science 289, 94 (2000).

[30] S. W. Lee, S. J. Park, E. E. B. Campbell and Y. W. Park, Nat. Comm. 2, Article Number: 220 (2011) (DOI: 10.1038 /ncomms1227).

[31] J. Svensson, N. Lindahl, H. Yun, M. Seo, D. Midtvedt, Y. Tarakanov, N. Lindvall, O. Nerushev, J. Kinaret, S. W. Lee and E. E. B. Campbell, Nano Lett. 11, 3569 (2011). 